\title{
A Study on the Sector Division for Effective Vessel Traffic Service : Focused on Daesan, Pyeongtaek and Inchon Harbour
}

\author{
Hyoung-Seon Yang* \\ * Division of Maritime Transportation System, Mokpo Maritime University, Mokpo, 530-729, Korea
}

\begin{abstract}
The national VTS was launched in 1993, and has adopted a harbour-oriented control method which is unable to consider enough characteristics of its work. However, for the past 17 years, the characteristics has changed due to increased amount of vessels. Up to now the domestic Vessel Traffic Service has adopted harbour-oriented control method which is unable to consider enough characteristics of its work. However, developed countries have carried out waters-oriented control method, according to the using areas of ships, to be well considered the characteristics of control for increasing efficiency of it. Especially, VTS of Daesan, Pyeongtaek and Inchon harbour can have confusions of control because of overlapped service areas of it. Therefore, in this paper suggested a new Sector Division that the relevants waters is divided into 3 operational Regions and these are divided into nine sectors again, for the purpose of improving the efficiency and the concentration of VTS.
\end{abstract}

Key words : Vessel Traffic Service, Vessel Traffic Control, Harbour-oriented Control, Efficiency of Control, Sector Division Control, Congestion Areas, Blind Areas of VTS

\section{Introduction}

Recently for the purpose of increasing the safety at sea and the efficiency of harbour administration, many countries has carried out Vessel Traffic Service(VTS) in the waters where the amount of traffic is concentrated, and has extended the range of VTS gradually. The main function of the VTS is to eliminate of the risk of traffic accidents in advance by doing close observation of ship's movements and exchanging the safe informations concerned about traffic management with each user of harbour. It is seriously affected by range, vessel traffic volume, the amount of wire traffic and the number of VTS operators due to the nature of controlling traffic.

Up to the now the domestic Vessel Traffic Service has adopted a harbour-oriented control method which is unable to consider enough characteristics of its work. However, developed countries have carried out ship's using the water area-oriented control method to be well considered the characteristics of control for increasing efficiency of it. Especially, Daesan VTS, Pyeongtaek VTS and Inchon VTS can have confusions of control because of overlapped service areas of them. It was reported that the volume of vessel traffic in these harbours is the second largest after Pusan harbour(Park, 2008).
Therefore, in this paper studied Sector Division control method to improve the efficiency and the concentration of VTS and to reduce workload of traffic control about the relevant waters.

\section{VTS affairs about the relevant waters}

\subsection{Analysis of workload in each VTS center}

For the analysis of workload in each domestic VTS center established and operated, we conducted a investigation on th basis of "Research for the efficient management of Vessel Traffic Service System"(the Ministry of Land, Transport and Maritime Affairs, 2007).

Table 1 shows workload of control in Daesan VTS, Pyeongtaek VTS and Inchon VTS. In the case of Inchon VTS, the average vessel traffic per hour, the average volume of communication in VHF per hour, the number of entering ships per week, the length of control waters and the quantity of marine accidents are above in comparison with national average. Above all, as the length of control waters in Inchon VTS center is 57 nautical miles, the longest waters in domestic except for Jindo VTS, the ability to concentrate in vessel traffic control service could weaken.

\footnotetext{
* Corresponding Author, epicyang@mmu.ac.kr 061)240-7178
} 
A Study on the Sector Division for Effective Vessel Traffic Service : Focused on Daesan, Pyeongtaek and Inchon Harbour

Table 1 Analysis of workload in each VTS center

\begin{tabular}{|c|c|c|c|c|}
\hline Item & $\begin{array}{l}\text { Inchon } \\
\text { VTS }\end{array}$ & $\begin{array}{l}\text { Daesan } \\
\text { VTS }\end{array}$ & $\begin{array}{l}\text { Pyeoun } \\
\text { gtaek } \\
\text { VTS }\end{array}$ & $\begin{array}{l}\text { National } \\
\text { average }\end{array}$ \\
\hline $\begin{array}{c}\text { The average vessels } \\
\text { of traffic control per } \\
\text { hour(vessels) }\end{array}$ & 49.1 & 22.3 & 6.8 & 33.26 \\
\hline $\begin{array}{l}\text { the average volume } \\
\text { of VHF } \\
\text { communications per } \\
\text { hour(times) }\end{array}$ & 36.9 & 9.1 & 10.1 & 26.46 \\
\hline $\begin{array}{l}\text { The entering vessels } \\
\text { per week(vessels) }\end{array}$ & 373 & 99 & 110 & 285 \\
\hline $\begin{array}{l}\text { The entering vessels } \\
\text { per week }\left(L^{2}\right. \\
\text { conversion) }\end{array}$ & 844.1 & 267.5 & 409.2 & 598.1 \\
\hline $\begin{array}{l}\text { The load of control } \\
\text { to over GT } 150 \text { tons }\end{array}$ & 170.8 & 215.0 & 118.0 & 172.8 \\
\hline $\begin{array}{c}\text { The ratio of } \\
\text { dangerous cargo } \\
\text { vessels }\end{array}$ & 19.3 & 76.77 & 30.00 & 31.16 \\
\hline $\begin{array}{c}\text { The load of control } \\
\text { to dangerous cargo } \\
\text { vessels }\end{array}$ & 151.2 & 187.5 & 110.0 & 158.3 \\
\hline $\begin{array}{l}\text { The length of traffic } \\
\text { control }\end{array}$ & $57 \mathrm{~nm}$ & $24 \mathrm{~nm}$ & $19 \mathrm{~nm}$ & *26.8 nm \\
\hline $\begin{array}{l}\text { The number of } \\
\text { traffic accidents }\end{array}$ & 45 & 1 & 1 & *23.5 \\
\hline $\begin{array}{c}\text { The number of } \\
\text { operators classified } \\
\text { by a duty }\end{array}$ & 5 & 2 & 2 & \\
\hline $\begin{array}{l}\text { The number of } \\
\text { blocks of control }\end{array}$ & 2 & 1 & 1 & \\
\hline $\begin{array}{l}\text { The average vessels } \\
\text { of traffic control per } \\
\text { hour in a block }\end{array}$ & 24.55 & 22.3 & 6.8 & \\
\hline
\end{tabular}

* Jindo VTS's data is excluded.

The average vessels of traffic control per hour divided in a block of control is Inchon VTS 25.5, Daesan VTS 22.3 and Pyeongtaek VTS 6.8 vessels. According to "Research report for the efficient management of Vessel Traffic Service System" in 2007, It was reported that the maximum vessels per hour to be able to control is 20 vessels. Taken in this light, Pyeongtaek VTS has enough spare vessels of traffic control but Inchon VTS and Daesan VTS are in excess of the maximum vessels of traffic control per hour. In comparison with the number of entering vessels of each harbour as table 2 shows, Daesan is 5,492, Pyeoungtaek is 373 and Dangjin steam power plant is 406 in 2008. For these circumstances, it is necessary that the management affairs of approaching waters to the Dangjin steam power plant is transfered from Daesan VTS to Pyeongtaek VTS.
Table 2 The number of entering vessels(unit : vessels)

\begin{tabular}{|c|r|r|r|r|r|r|}
\hline Harbour & $\begin{array}{c}\text { Capa } \\
\text { city }\end{array}$ & \multicolumn{1}{c|}{04} & \multicolumn{1}{c|}{05} & '06 & '07 & ’08 \\
\hline Daesan & 21 & 4,386 & 4,587 & 4,870 & 5,270 & 5,492 \\
\hline Pyeoungtaek & 2 & 294 & 310 & 259 & 334 & 373 \\
\hline $\begin{array}{l}\text { Dangjin power } \\
\text { plant }\end{array}$ & 2 & 247 & 297 & 282 & 342 & 406 \\
\hline
\end{tabular}

\subsection{Analysis for ranges of operation in each VTS center}

The Fig. 1 shows investigated tracks of vessels during the peak-time 3 days in 2009(Daesan Port Authority, 2009) and the Fig. 2 shows that we have investigated ranges of control, the congestion areas of vessel traffic and the blind areas(out of bounds of VTS's ranges) of control at the present time in case of Inchon VTS, Daesan VTS and Pyeongtaek VTS. The congestion areas are approaches to Ando island, Daesan harbour, Janganseo island, Palmido island, Inchon bridge and the front area of a gate to Inchon dock. It is necessary to demand high density management in these areas(Kim, 1998). Especially, the area, from Ando island to Janganseo, is the place where the using waters of ship overlapped and vessels using the area is controlled by each VTS center according to entering the port. Thus confusions of control can take place and works for preventing traffic accidents in emergency can be difficult. Additionally, the area is the congestion of vessel traffics. There are also a lot of vessels waiting for entry into Inchon, Daesan and Pyeongtaek port. As the reasons mentioned above, we suggest the Sector Division control method to improve the efficiency and the concentration of vessel traffic service to the relevant waters.

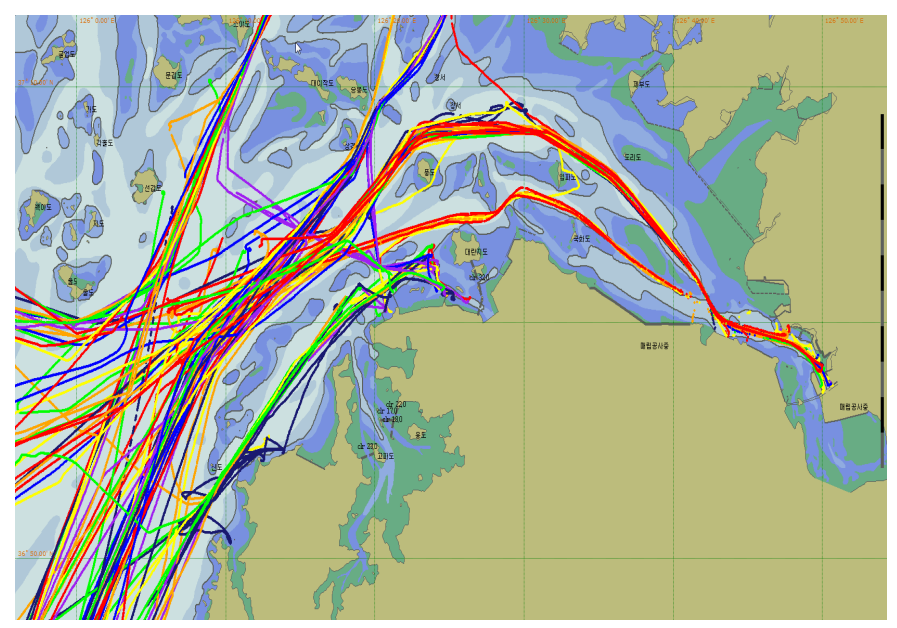

Fig. 1 A track chart of vessels during the peak-time 3 days 


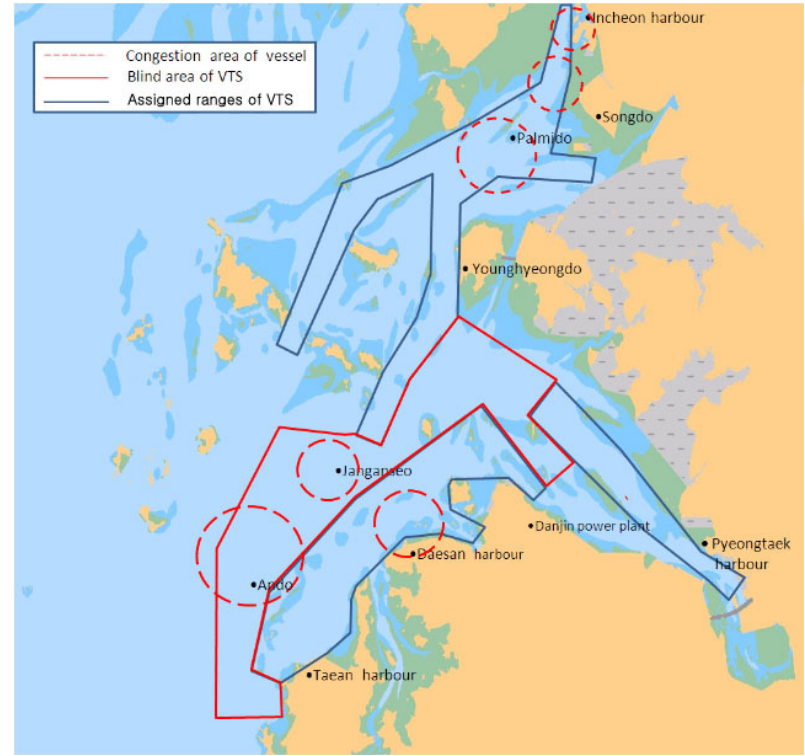

Fig. 2 Ranges of operation in each VTS center

\section{An instance of sector division control}

The sector division control method has been applied at Hongkong VTS, Singapore VTS, Tokyo VTS, the narrow channel of Turkey and Istanbul VTS, to improve the efficiency of vessel traffic control in the area where the vessel traffic is concentrated and the using waters of ship is overlapped. We will take a close look at vessel traffic control of Singapore harbour which has the highest density vessel traffic.

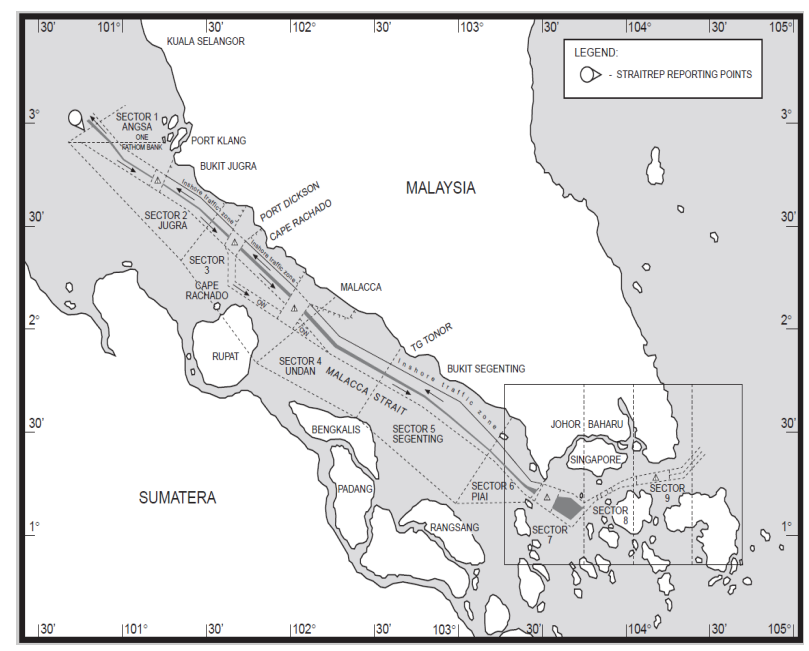

Fig. 3 Vessel traffic control according to sector in Singapore

The Singapore Strait has the longest length in the world as it is the entrance of Singapore port and a important passage connecting between the Far East of Asia and the Middle East of Asia. As Fig.3 indicates, the Singapore VTS manages vessel traffic both of the strait and the harbour. The Singapore strait was partitioned off the area into three sectors. A sector has about $20 \mathrm{~nm}$ range, as seen that the length of each sector is Sector7 $22 \mathrm{~nm}$, Sector8 $20 \mathrm{~nm}$, Sector9 $23 \mathrm{~nm}$. As Fig. 4 indicates, the inside of Singapore harbour was partitioned into four regions. For traffic control inside the harbour, four workstations and nine VHF channels are prepared and four operators use each workstation them to do job at the same time. Thus it is possible to increase the amount of traffic control per hour.

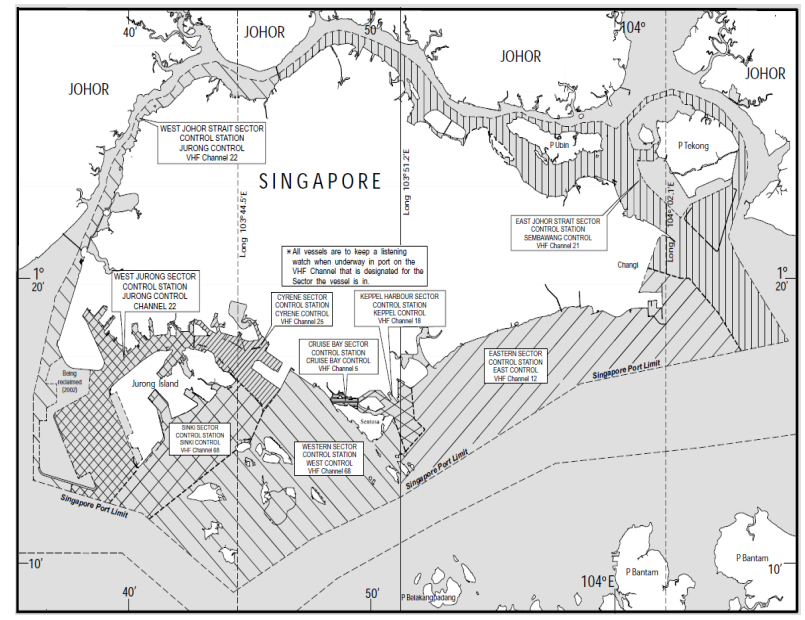

Fig. 4 Vessel traffic control according to region in Singapore

\section{Sector division for vessel traffic service}

We made observations of the present status and problems concerned with traffic control in the relevant waters above. There is a difference of the amount of work to control traffic and there are several blind areas from range of control. As we have seen, the present range of control that can be made a confusion in the nature of work is needed to be separated into several sectors.

In the matter of Vessel Traffic Service, the necessity of it was mentioned at International Conventions such as SOLAS and STCW, but definite articles was written in "IALA, VTS manual" or "IMO protocol". Besides, the most fundamental international standards concerned with the division of range in traffic control can be "IMO Assembly Resolution A857(20)". With the respect to the division of the range, inclusive guides and points to be considered are such as follows.

- If possible, regions and sectors to be separated in a few.

- Avoid the place where a ship alters her course.

- Avoid the place where vessel traffic is high density. 
A Study on the Sector Division for Effective Vessel Traffic Service : Focused on Daesan, Pyeongtaek and Inchon Harbour

- Avoid the place where the passage meets or crosses.

- Each sector and region has to be named.

- Bounds have to be declared at suitable sailing directions and "World VTS Guide"

Considering International Standards and Guides, it is desirable that the relevant waters is divided into three regions and each region is divided into several suitable sectors again for the high concentration in traffic control.

\subsection{The region division of VTS}

As Fig.5 shows, we make a proposal that the relevant waters is divided into three regions. The Region1 has the control range from Ando island to the entrance to the East Lane of Inchon including Daesan harbour and Taean harbour. The Region2 has the control range from the starting point of the East Lane of Inchon to the Baekam lighthouse lied east of Youngheoungdo island including Pyeoungtaek harbour and the Dangjin steam power plant. The Region3 has the control range from the Baekam lighthouse to Palmido island including Inchon harbour and the West Lane of Inchon.

In case of a ship passing the bound of each region, the ship has to report her position to the operational VTS center in accordance with assigned procedures. Also, It is desirable that a ship passing the boundary of each region reports her position to only the operational VTS center for the reduction of wire traffic.

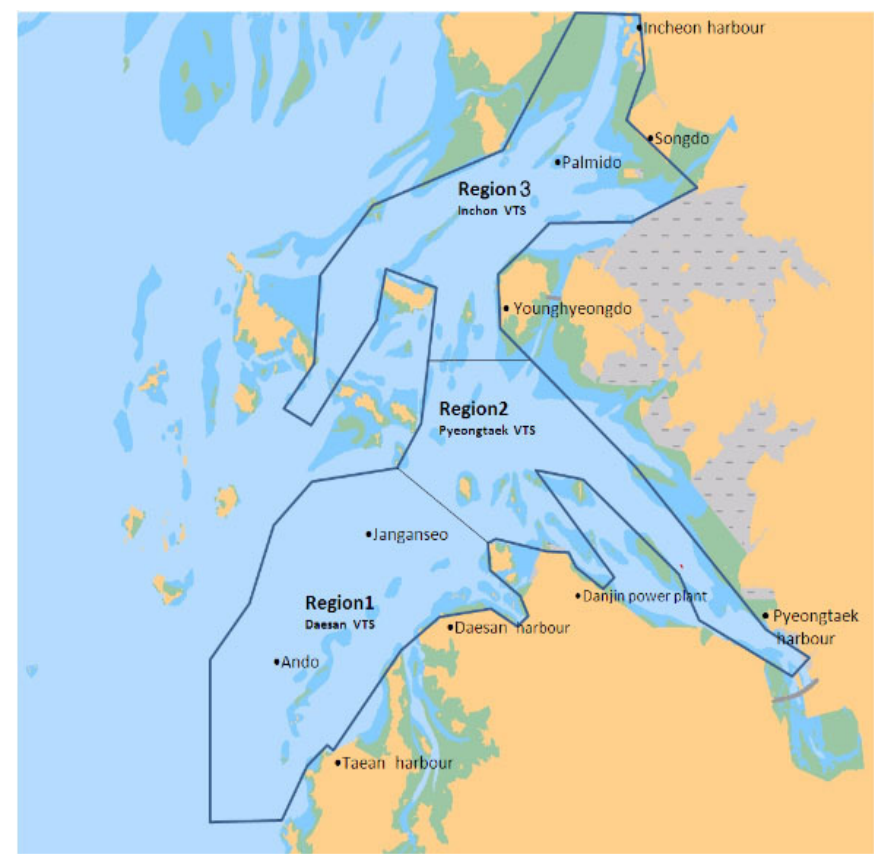

Fig. 5 A proposal for division of bounds of VTS

\subsection{The sector division of VTS}

We make a proposal that Regions suggested above is divided into nine sectors again, and that was showed in Fig.6. The detailed control plan is such as follows.

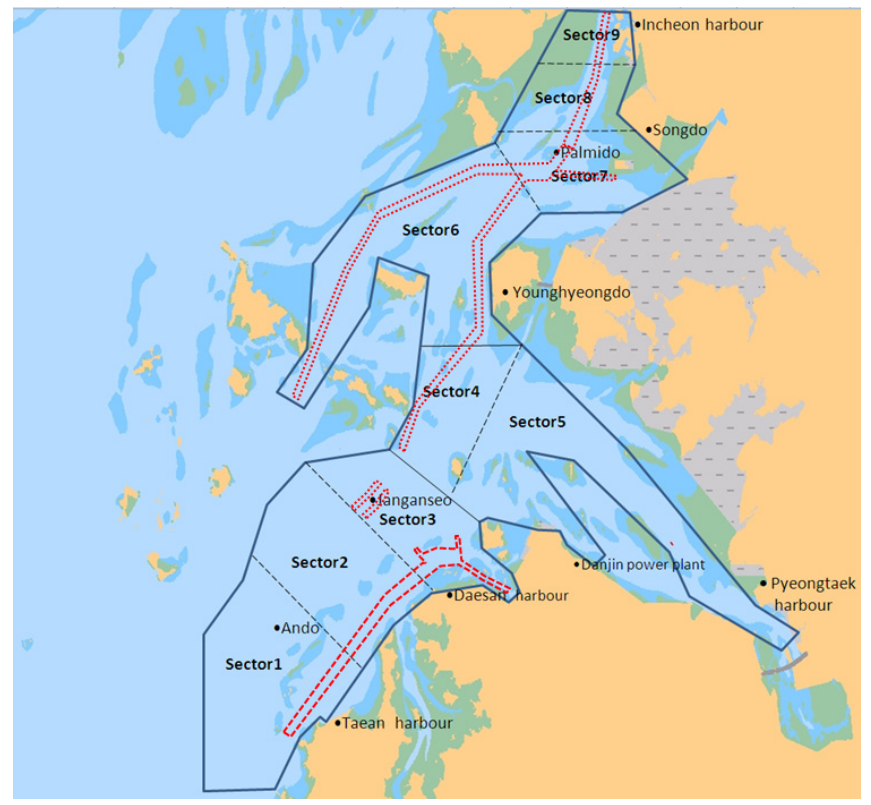

Fig. 6 A proposal for sector division of VTS

- The Sector1 has the control range from Shindo pilot station to Ando island including the entrance of Daesan harbour and Taean harbour. As the Fig. 1 shows, this area has the plenty of vessels for the purpose of entering or leaving the relevant ports. Daesan VTS center has operational competence over this sector.

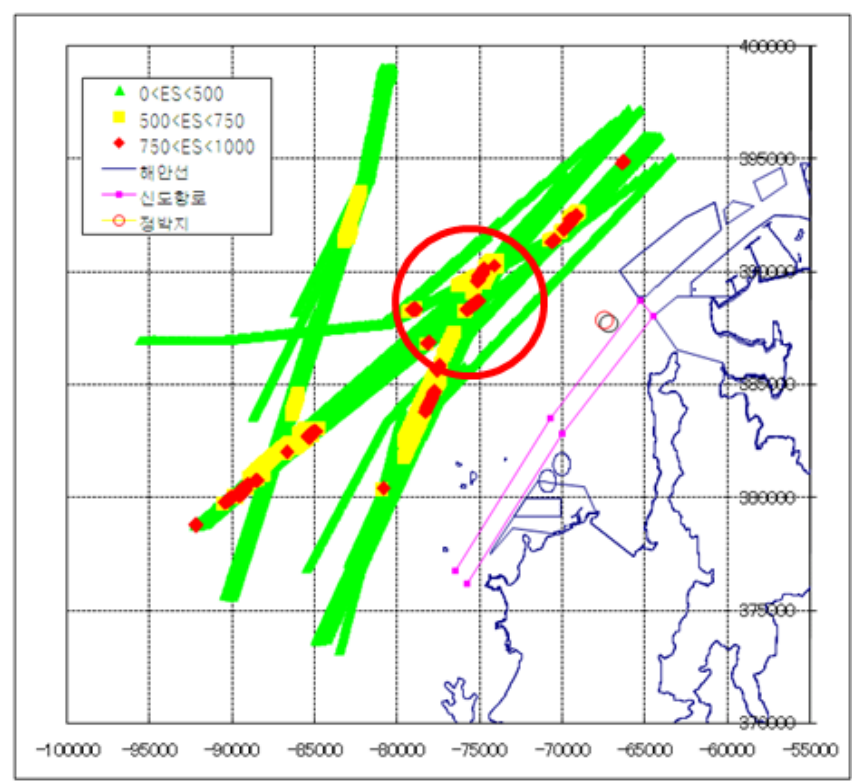

Fig. 7 Analysis of ES(Environment Stress) in the Sector2 
- The Sector2 has the control range from Ando island to the east front of Janganseo TSS, including a part of Daesan harbour. As the Fig. 1 shows, there are the plenty of vessels entering/leaving/waiting the relevant ports. Also, the value of ES(Environment Stress), ES means navigational load of ship, is high as the Fig. 7 shows(Daesan Port Authority, 2009). Daesan VTS center has operational competence over this sector.

- The Sector3 has the control range from the east front of Janganseo TSS to the entrance to the East Lane of Inchon including a part of Daesan harbour. As the Fig. 8 shows, there are the plenty of vessels entering/leaving the relevant ports in this sector. Also, this sector is the place where the passage meets or crosses including TSS.(Daesan Port Authority, 2009). Daesan VTS center has operational competence over this sector.

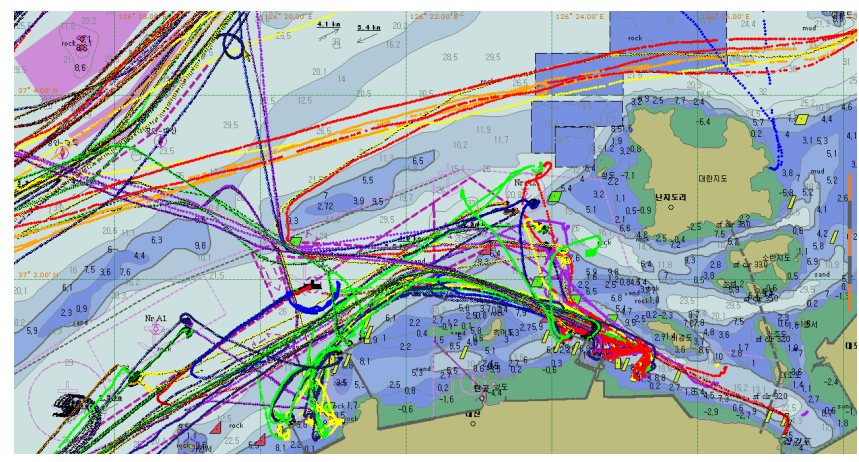

Fig. 8 The track chart of the Sector3 during the peak-time 3 days

- The Sector4 has the control range from the entrance to the East Lane of Inchon to Baekam lighthouse including a narrow channel. As the Fig. 1 shows, there are vessels entering Inchon and Pyeongtaek harbour in this sector. Pyeongtaek VTS center has operational competence over this sector.

- The Sector5 has the control range of the front area of Pyeongtaek and Dangjin harbour. This sector has lots of vessels entering or leaving the Pyeongtaek and Dangjin harbour. Pyeongtaek VTS center has operational competence over this sector.

- The Sector6 has the control range from Baekam lighthouse to Bukjangjaseo including the West Lane of Inchon harbour. There are lots of waiting vessel to enter into the Inchon port and lots of entering/leaving. Also, this sector includes a place where the vessel traffic is high density. Pyeongtaek VTS center has operational competence over this sector.

- The Sector7 has the control range from Bukjangjaseo to Palmido. There are lots of waiting vessel to enter into the Inchon port and lots of entering/leaving. Also, this sector includes the place where the vessel traffic is high density and the place where the passage meets or crosses. Inchon VTS center has operational competence over this sector.

- The Sector8 has the control range between the front and the rear area of Inchon Bridge. The width of fairway to pass the bridge is about $625.5 \mathrm{~m}$, and the risk of collision could increase. therefore, the concentrated traffic control is demanded in this sector. Inchon VTS center has operational competence over this sector.

- The Sector9 has the control range from the rear area of Inchon Bridge to SK oil jetty pier. including Inchon Dock. this sector includes the place where the vessel traffic is high density and the place where the passage meets or crosses according to lots of vessel entering or leaving the harbour. therefore, the concentrated traffic control is demanded in this sector. Inchon VTS center has operational competence over this sector.

- In case of a ship passing the boundary of each Sector, the ship have to report her position to the operational VTS center in accordance with assigned procedures. Also, It is desirable that a ship passing the boundary of each Sector reports her position to only the operational VTS center for reducing the volume of communications.

- In case of a ship passing between sectors in same Region, the operational VTS center provides her with informations about safe navigation.

\subsection{A investigation of the proper number of operators}

Frist of all, sharing all informations between VTS centers is needed for implement of new traffic control method by Sector Division. If the Sector Division Control is adapted, Inchon VTS can concentrate more effective traffic control with present staffs because of the deduction of operational ranges. The operational range of Pyeoungtaek VTS center is extended, but the average vessels of traffic control per hour is enough in comparison with the national average of it, so that Pyeoungtaek VTS center can operate traffic control with present staffs. Near the waters of Ando and Jangandseo island where all ships are concentrated are added into the operational range of Daesan VTS center, so that the average vessels of traffic control per hour will be very increased. Also, to control vessel traffics in three sectors, it is desirable that operational workstations have to be installed from two workstation at present to three 
A Study on the Sector Division for Effective Vessel Traffic Service : Focused on Daesan, Pyeongtaek and Inchon Harbour

workstations. Therefore, in case that people to operate workstations work a standard 40-hour week, the legal working hour according to the calculation of proper VTS operator guide by $\operatorname{IALA}(3$ workstation $\times 5.29$ persons $=$ 15.87 persons). For Operators is manned 24 hours a day, the needed operators will be 16 persons. Daesan VTS center was manned with eight operators, two repairers and three administrators in present. If vessel traffic service is carried out by each Sector Division, the center has to increase 8 operators at least.

\section{Conclusions}

Vessel Traffic service should well reflect the characteristics of control range, vessel traffic volume, the amount of wire traffic, the number of VTS operators and etc. for the effective control. The national VTS was launched 17 years ago, and has adopted harbour-oriented control method which is unable to consider enough characteristics of its work. However, for the past 17 years, the characteristics has changed due to increased amount of vessels. Therefore, It is time researches is needed for improvement of the efficiency of traffic control. Especially, VTS of Daesan, Pyeongtaek and Inchon harbour can have confusions of control because of overlapped serivice areas of VTS, so that we studied on sector division for effective vessel traffic service focused on those areas.

We figured out areas of vessel congestion and blind areas of traffic control throughout the status analysis of the relevant traffic control. The congestion areas are approaches to Ando island, Daesan harbour, Janganseo island, Palmido island, Inchon Bridge and the front area of a gate to Inchon dock. It is necessary to demand high density management in these areas. Especially, the area, from Ando island to Janganseo, is the place where the the using waters of ship overlapped and the vessel using this area is controlled by each VTS center according to ship's entering the port. Thus confusions of control can take place and works for preventing traffic accidents in emergency can be difficult. Additionally, the area, from Ando island to Janganseo, is the congestion of traffic and the blind area of vessel traffic control. There are a lot of vessels waiting for entry into Inchon, Daesan and Pyeongtaek port also.

As the reasons mentioned above, we suggested the Sector Division method to improve the efficiency and the concentration of vessel traffic service. Considering International Standards and Guides, it is desirable that the relevant waters is divided into three regions and each region is divided into several suitable sectors again for the high concentration in traffic control. Additionally, had a consideration concerned with the proper number of operators. If the Sector Division of VTS is implemented, Inchon VTS can concentrate more on traffic control with present staffs because of the deduction of overlapped operational ranges. Especially, the merit of suggested Sector Division Control method is that operators and navigators can clearly find out the movements of all ships by watching VHF.

Frist of all, sharing all informations on traffic control between VTS centers is needed for implement of VTS by Sector Division. Therefore, studies to standardize exchanging data and to select the effective communication protocol must continue in future.

\section{References}

[1] Daesan Port Authority(2009), "Research for Evaluation of Vessel Traffic Environment Focused on Daesan Harbour and near waters".

[2] IALA, "VTS Manual(2008, Draft)", pp 13 130.

[3] IMO(1998), "Guidelines for Vessel Traffic Service", IMO Assembly Resolution A857(20).

[4] Kim, S.H. and Park, J.S.(1998), "A Study on the Efficient Operation of VTS in Inchon", Proceedings of the Korean Institute of Navigation Research Conference, Vol. 8, pp.11 25 .

[5] Park, S.Y., Park, J.S., Kang, J.G. and Park, Y.S.(2008), "A Study on Evlauation of Harbour VTS Operators' Workload by the Analysisi of Marine Traffic”, Journal of Navigation and Port Research, Vol.32, No. 8, pp 569 $\sim 576$.

[6] The Ministry of Land, Transport and Maritime Affairs(2007), "Research for the efficient management of Vessel Traffic Service System".

Received 9 April 2010

Revised 22 June 2010

Accepted 23 June 2010 